\title{
AN ORIGINAL HISTOLOGICAL METHOD FOR STUDYING THE VOLAR SKIN OF THE FETAL HANDS AND FEET
}

\author{
Henrieta Seidenberg-Kajabova, Viera Pospisilova*, Valeria Vranakova, Ivan Varga
}

\author{
Department of Histology and Embryology, Faculty of Medicine, Comenius University in Bratislava, Sasinkova Street 4 , \\ 81108 Bratislava, Slovakia \\ E-mail:viera.pospisilova@fmed.uniba.sk
}

Received: January 28, 2010; Accepted with revision: August 17, 2010

Key words: Histological serial sections/Dermatoglyphic pattern development/Volar pads/Volar skin of human fetal hands and feet

Aims. The human fetal period of life is when there is complete development of the dermatoglyphic pattern. However, to date not enough is known about the differentiation of the papillary terrain during prenatal life and which mechanisms are involved in this differentiation. The aims of the present study are to contribute to the clarification of the embryogenesis of the papillary ridges and to compare their development on the hands and feet.

Methods. The hands and feet of 35 human embryos and fetuses were examined in the present study. We used a new and original method of orientation. The right hand with right foot or left hand with left foot of each embryo/fetus were placed together into one paraffin block. Three different planes of orientation were used.

Results. Volar pad development and papillary ridge formation are identical on hands and feet, but the developmental stages on feet lag one week behind those of hands. Papillary ridge embryogenesis follows the cranio-caudal developmental direction. After developmental week 14 the configuration of the future dermatoglyphic pattern has already ocurred at the dermo-epidermal junction. We consider the $6^{\text {th }}$ month of prenatal development to be the gestational age when the papillary ridge development is completed.

Conclusion. Our observations lead to the conclusion that the increased vascularization of dermis considerably affects papillary ridge formation.

\section{INTRODUCTION}

The development of papillary ridges is preceded by the formation of eminences, so-called volar pads on the hands and feet. These pads vary in number, size, and shape among mammals ${ }^{1}$. In human embryos, the first pads are formed as berry-shaped accumulations of mesenchyme connective tissue on the ventral proximal regions of the fingers. Later they form in the interdigital, thenar, and hypothenar regions of palms and soles. Volar pads first appear as discrete elevations on the palm around 6.5 weeks after fertilization, followed on the digits by apical pads about one week later. The distal finger pads are maximally developed during the $12^{\text {th }}$ week. Then they move and spreads at the top of fingers are the sites of papillary ridge development ${ }^{2,3}$. Papillary ridge formation is preceded by four events: mesenchyme condensation, epidermal proliferation, skin innervation, and Merkel cell differentiation ${ }^{4,5}$.

The epidermal-dermal fit establishes the unique patterns of ridges and grooves (dermatoglyphs) present on the surface of the plantar and palmar epidermis. The pattern of the epidermal ridges on our fingers, palms and soles, colloquially called fingerprints, is a part of our every-day life. Scientific interest in dermatoglyphs has been related mainly to their aberrations in numerous congeni- tal malformations ${ }^{6}$. Also are discussed their association with early prenatal undernutrion ${ }^{7}$, adult blood pressure ${ }^{8}$ or insulin dependent diabetes ${ }^{9,10}$. For this reasons, the dermatoplyphs can be a significant marker of prenatal events and may provide a useful tool to investigate prenatal developmental plasticity with potential in clinical medicine. In 1892 Sir Francis Galton demonstrated that epidermal ridge configurations did not change throughout postnatal life and their development is determined by multiple genes ${ }^{11}$. From this time, the dermatoglyphics have been studied by forensic scientist, as well as by population genetics and anthropologists, for identify the possible differences between isolated ethnic or genetic populations ${ }^{12-14}$ or for identifications of individuals ${ }^{15,16}$.

The embryogenesis of papillary ridges has been studied by various authors with different methods. The first relevant embryological studies, which are cited in recent times too, are from Bonnevie ${ }^{11,17,18}$ and Cummins ${ }^{19,20}$ from the $30^{\text {th }}$ years of the $20^{\text {th }}$ century. In next years, the embryologic development of hands and feet were studied by different methods:

- Classical methods of light microscopy $y^{2,3,21}$

- Methods of scanning electron microscopy ${ }^{22,23}$

- Methods of transmission electron microscopy ${ }^{24}$

- Methods of immunohistochemistry (for identify structures of afferent nerves and Merkel cells) $)^{25,26}$ 
- Study of dermal surface after exposed by potassium hydroxide solution and several days by formalin. After this procedure the epidermis could be easily flaked off from the dermo-epidermal junction and the dermal ridges can be metachromatically stained with toluidine blue $^{27}$

- Methods of mathematical analysis ${ }^{14}$.

In our study, we introduced a new and original method of orientation of fetal hands and feet. The aim of this original method was to study paralelly hands and feet of one embryo/fetus in one slide. Three different planes of orientation of sectioning were used.

\section{MATERIAL AND METHODS}

The hands and feet of 35 human embryos and fetuses were examined in the present study. The embryos and fetuses came from the collection of the Department of Histology and Embryology, Medical Faculty, Comenius University in Bratislava, Slovakia. The gestational age was estimated either by the menstrual age, or by the measuring of the heel-toe lengths using Streeter's standards ${ }^{28}$. The gestational age of all embryos and fetuses was ranged between $7^{\text {th }}$ to $26^{\text {th }}$ weeks.

The specimens were fixed in various fixatives (a mixture of alcohol-formalin-acetic acid, Baker's formalin or Bouin's fixative) and prepared using general histological methods (embedding into paraffin, sectioning into serial sections of 7-10 $\mu \mathrm{m}$, staining and mounting with cover slip).

We used a new and original method of orientation of human fetal hands and feet. The right hand with right foot or left hand with left foot of each embryo/fetus were placed together into one paraffin block for sectioning. In a one paraffin block in order to achieve three planes for sectioning (transversal, volar, and sagittal) were used (Fig. 1). Each of these three planes was oriented to the long axis of both hands and feet. An individually designed placement of hands and feet was adapted to the quality and the size of studied specimens. The serial sections were stained for structural demonstration using different histological staining methods: hematoxylin and eosin, Masson's trichrome method for collagen fibers, Periodic Schiff Reaction for polysaccharides visualisation and impregnation of neurofibrils after Holmes. A technique developed by Okajima ${ }^{29}$ was used in addition to the histological method. The epidermis was brushed off the macerated volar skin allowing for examination of the dermal surface.

\section{RESULTS}

From the $7^{\text {th }}$ week of prenatal development volar pads on fingers of hands and feet were observed as local elevations of the surface, formed by accumulation of mesenchyme under the basal epithelial layer (Fig. 2). They were richly supplied by enlarged blood sinuses. The develop-

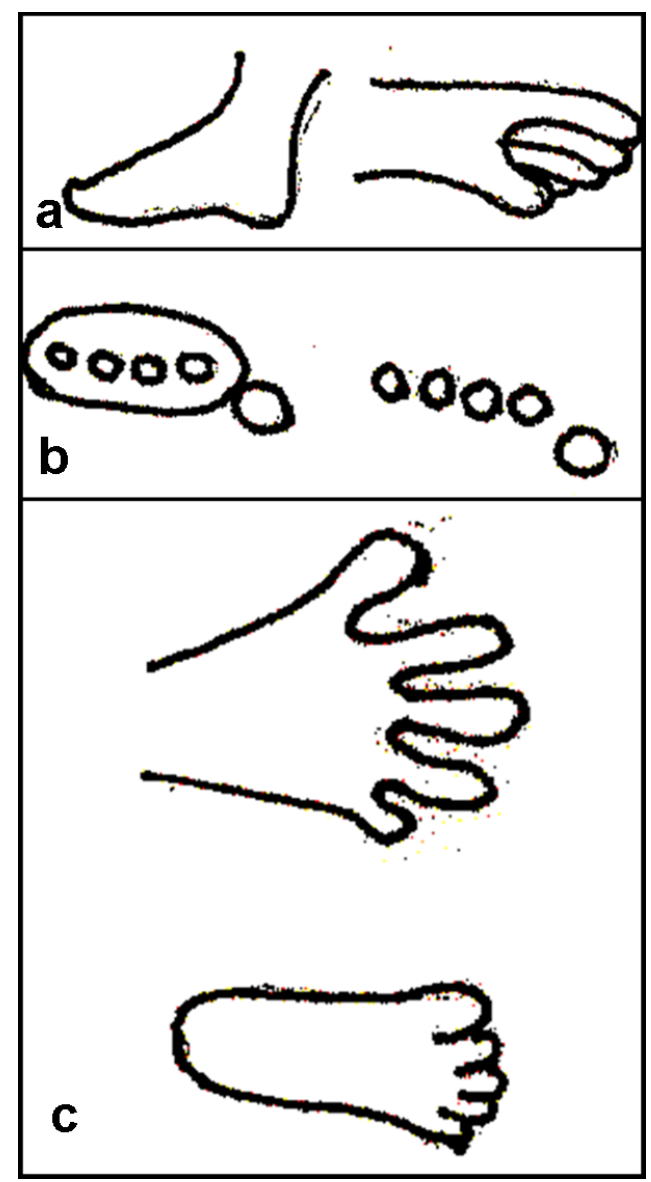

Fig. 1. Different placement of hands and feet into one paraffin block:

a - On the lateral side, to cut sagittal sections.

b - Vertically to cut transversal sections.

c - On volar surface parallel to surface to cut tangential sections.

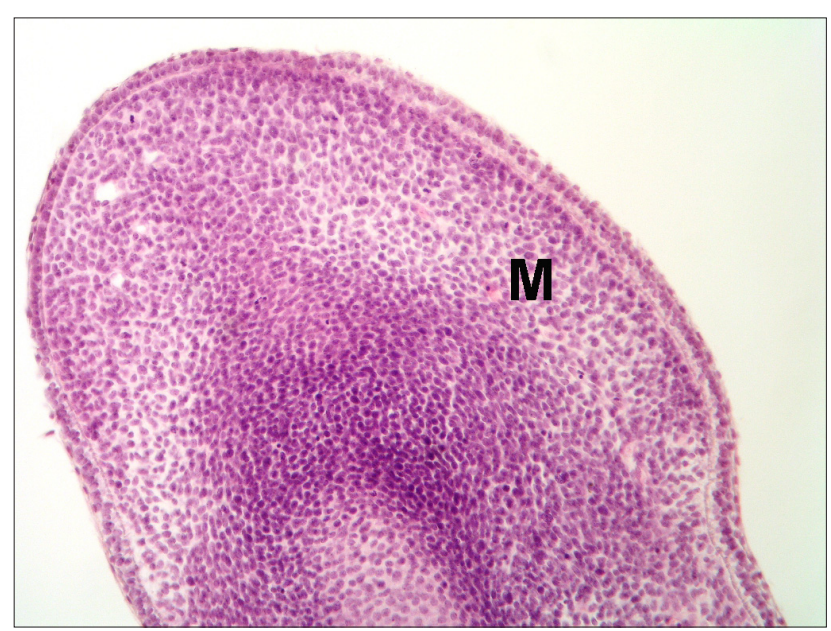

Fig. 2. Sagittal section through the pad region of the toe of human embryo in the $8^{\text {th }}$ week of development. Proliferating mesenchymal cells (M) under epidermis forming the future finger pad. (hematoxylin and eosin, Magn. 200x). 




Fig. 3. Scheme of successive distal volar pad development.

1 - Pad prominence ( $7^{\text {th }}$ to $10^{\text {th }}$ week)

2 - Growth over the tip of the finger $\left(11^{\text {th }}\right.$ week $)$

3 - Pad regression $\left(12^{\text {th }}\right.$ and $13^{\text {th }}$ week $)$

4 - Nail furrow (14 ${ }^{\text {th }}$ week)

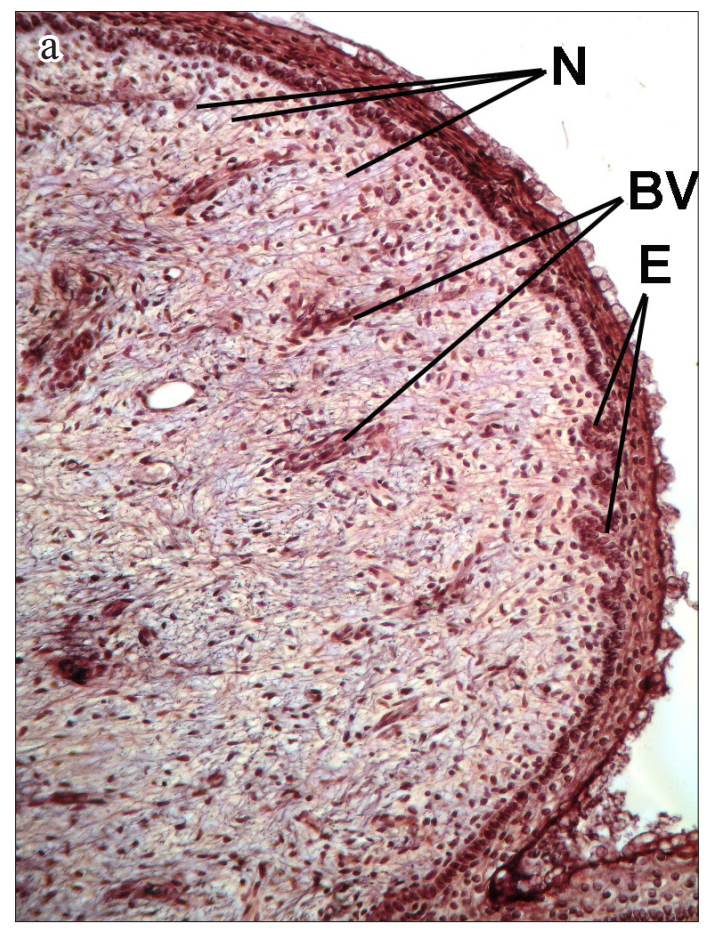

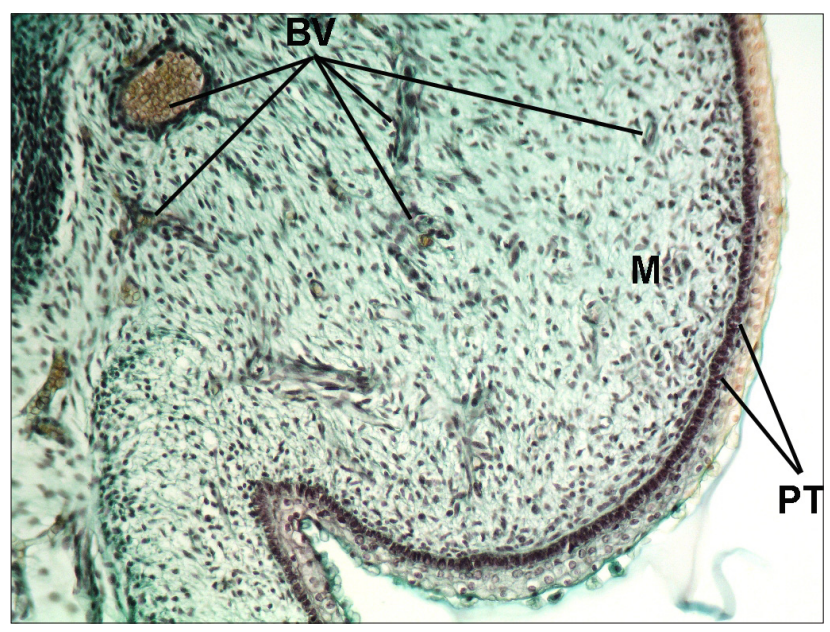

Fig. 4. Sagittal section through the pad region of the toe of human fetus in $10^{\text {th }}$ week of development. Accumulation of the mesenchyme (M) and numerous blood vessels (BV) form the full developed finger pad. The beginning of the papillary ridge development (formation of papillary terrain, PT) as an undulation of the basal layer of epidermis is seen. (hematoxylin and eosin, Magn. 200x).

Fig. 5a. Sagittal section through the pad region of the toe of 12-week-old fetus. The early stage of papillary ridge formation: epidermal glandular folds throughout the entire pad surface proliferate into the dermis forming the epidermal ridges (E). The blood vessels (BV) and fine nerve fibers (N) are oriented radially epidermis. (impregnation of neurofibrils after Holmes, Magn. 200x).

Fig. 5b. Finger pad region in the same developmental stage as Fig. 5a. All epidermal cell layers (E), and the undulated basal membrane (BM) shows positive reaction for polysaccharides (probably glycogen). In the developing dermis blood vessels are present (BV). (combination of PAS reaction and Masson's trichrome method, Magn. 400x).

mental direction of the finger pads was from the first to the fifth finger. These pads were formed on the proximal and distal finger phalanges. The maximal development of the distal finger pads was reached in weeks 12 and 13 respectively. Thereafter top regression of pad occurred (Fig. 3). In the third month, the pads of interdigital palm spaces also appeared. In our material no central palm pad was observed. Feet pads were developed in the same direction as the hand pads, but approximately a week later. They were more expansive and one pad was also present in the calcar area. From the $11^{\text {th }}$ week the vascularization of the dermal connective tissue weakened considerably. 


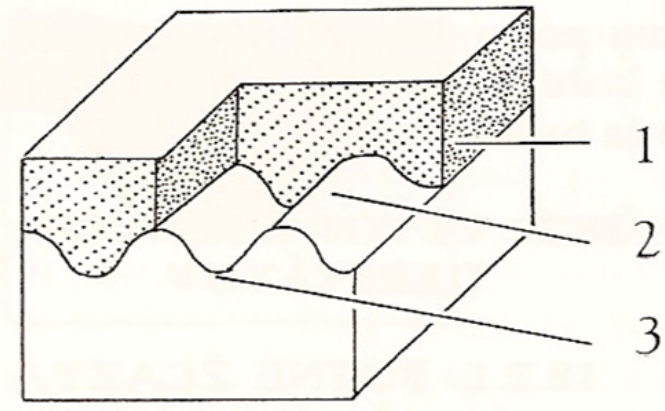

A

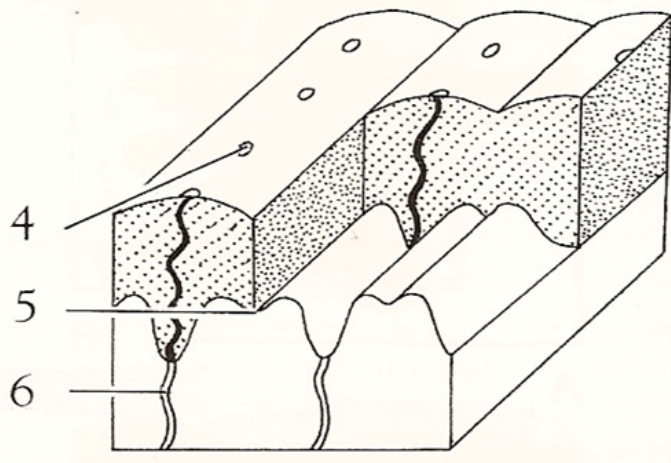

B

Fig. 6. Development of an epidermal-dermal junction in $3^{\text {rd }}$ gestational month $(A)$ and $7^{\text {th }}$ gestational month (B).

1 - Epidermis

2 - Primary dermal ridge (crista corii)

3 - Epidermal glandular fold of epidermis

4 - Sweat pores on the epidermal ridge surface

5 - Epidermal furrow fold of epidermis

6 - Sweat gland primordium

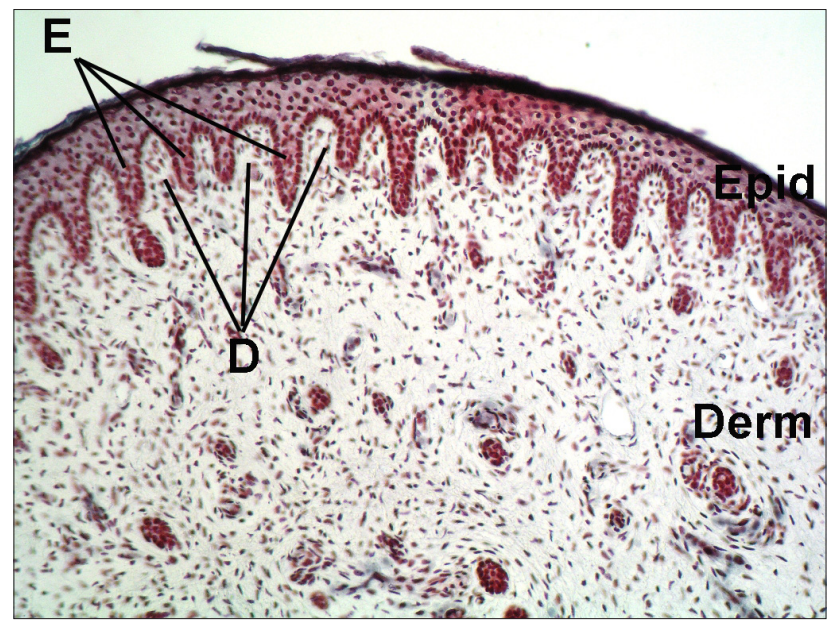

Fig. 7. Transversal section through the epidermal (Epid) - dermal (Derm) junction shows the papillary ridge formation: epidermal glandular folds (E) and primary dermal ridges (D) of 13-week-old fetus. (Masson's trichrome, Magn. 200x).

This could be connected with the regression of finger pads after $3^{\text {rd }}$ month. The volar pads completely disappeared in the following month.

Papillary ridge differentiations begin as an undulation of the epidermal basal layer in the pad region in $\mathbf{1 0}^{\text {th }}$ gestational week (Fig. 4). The proliferation of cells from the basal epidermal layer (consist of columnar cells) into the underlying dermis formes epidermal glandular folds. In developmental week 12 the early stages of papillary ridge formation were observed (Fig. 5a and 5b). The dermis forms ridges projecting upward into the epidermis, the so-called primary dermal ridges (Fig. 6 and 7).

The epidermal glandular folds with primary dermal

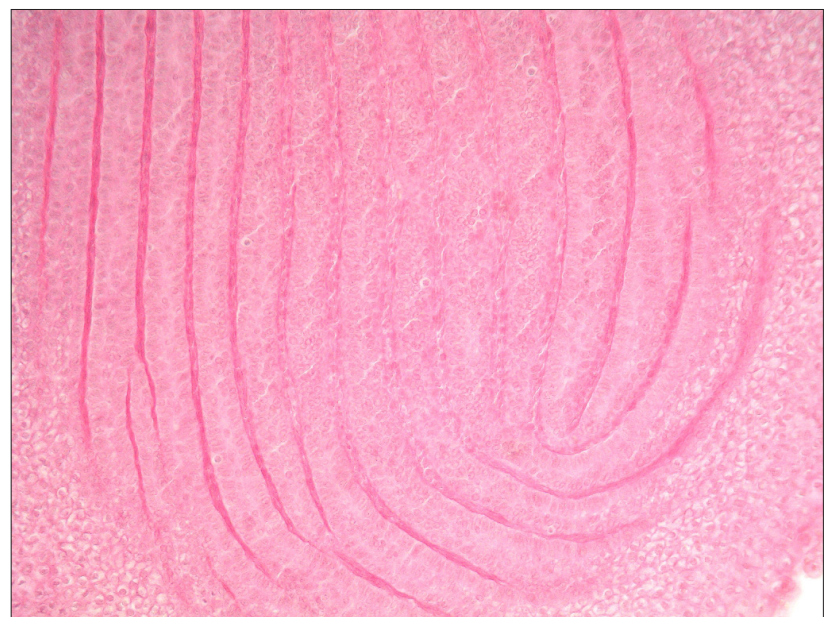

Fig. 8. Tangential section through the ventral surface of finger pad of 15-week-old fetus. Dark stained lines are the epidermal glandular folds arranged as the dermatoglyphic pattern called loop. (hematoxylin and eosin, Magn. 400x).

ridges were differentiated in week 14. The configuration of dermatoglyphic pattern (loop, whorl and arch) already occurred during this developmental period. A configuration of loop was observed under light microscope in the tangential plane sections of volar skin in Fig. 8.

The differentiation of the epidermal glandular folds and primary dermal ridges proceeded in radio-ulnar or tibio-fibular directions. The directions of the epidermal ridge development could be seen on Fig. 9.

The skin grew and distances between the epidermal glandular folds increased. They were separated by wider primary dermal ridges. During the $\mathbf{1 6}^{\text {th }}$ and $17^{\text {th }}$ week a strong vascularization of dermal connective tis- 


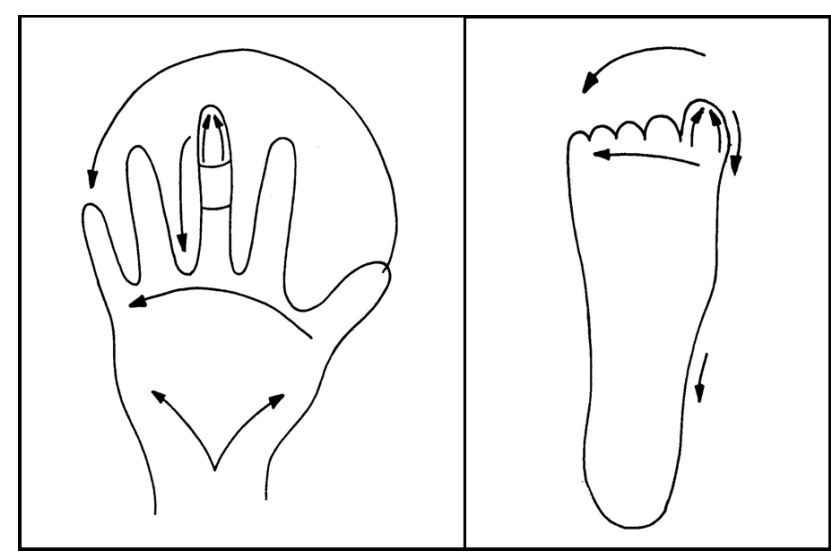

Fig. 9. Arrows show a direction of the papillary ridge development.

Fingers of hand and toes of foot: from the border to the central part of phalang, from the distal to the proximal phalang, from the first to the fifth finger/toe

Hand: fingers - interdigital spaces - center of palm - thenar and hypothenar

Foot: toes - interdigital spaces - calcar - thenar and hypothenar

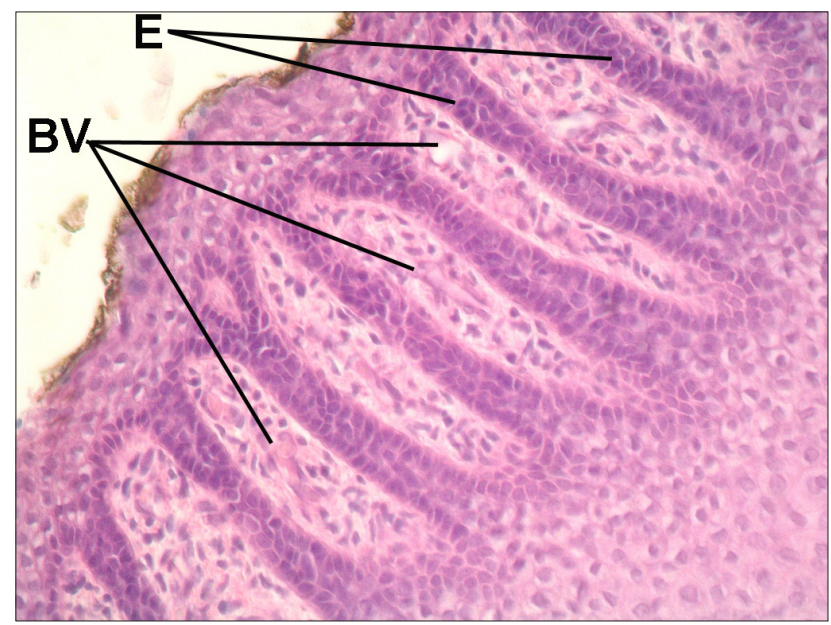

Fig. 10. Tangential section through the ventral surface of a finger pad of 16-week-old fetus. Between dark stained parallel arranged epidermal glandular folds (E). A strong vascularization (blood vessels, BV) of primary dermal ridges could be seen (hematoxylin and eosin, Magn 400x).

sue beneath the epidermis reappeared (Fig. 10 and 11). Epidermal furrow fold formation began at this stage. Epidermal furrow folds separate primary dermal ridges and in this way transformed them into double parallel ridges - secondary dermal ridges. Furrow folds were observed on the slides from week 19 (Fig. 12). A month later the furrow folds and secondary dermal ridges were present throughout the entire volar skin of hands and feet (Fig. 13). At the same time, the transversal dermal fur-

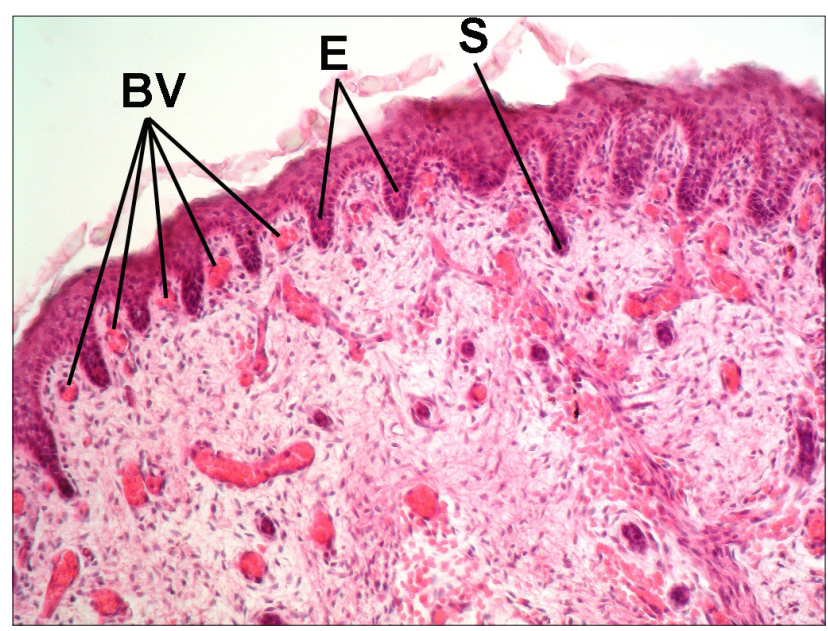

Fig. 11. Transversal section through the finger of 18-weekold fetus. From the epidermal glandular folds (E) the primordia of sweat glands $(\mathrm{S})$ grow into dermis. Between the primary dermal ridges enlarged blood vessels (BV) are present. (hematoxylin and eosin, Magn. 200x).

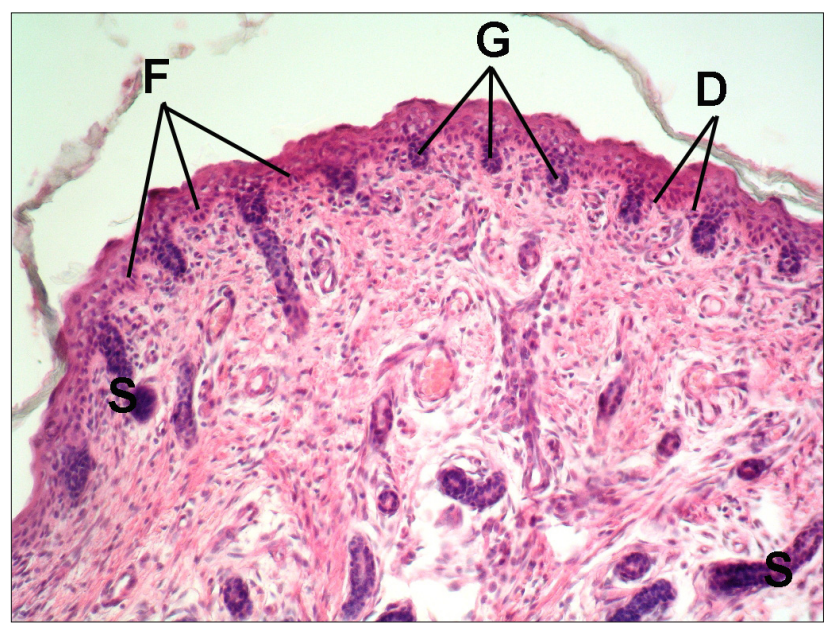

Fig. 12. Transversal section through the dermal-epidermal junction of skin shows a later stage of papillary ridge formation (20-week-old fetus). From the epidermal glandular folds $(G)$ the primordia of sweat glands (S) grow into dermis. Epidermal furrow folds $(\mathrm{F})$ proliferate from epidermis into dermis. These folds split the primary dermal ridges into double parallel ridges, so-called secondary dermal ridges (D). (hematoxylin and eosin, Magn. 200x).

rows (sulci transversi corii) appeared on the secondary dermal ridges and the first dermal papillae (papillae corii) were formed (Fig. 14). The papillary ridge formation was identical on palms and soles compared with hands. There was approximately a one week delay in the feet development. 


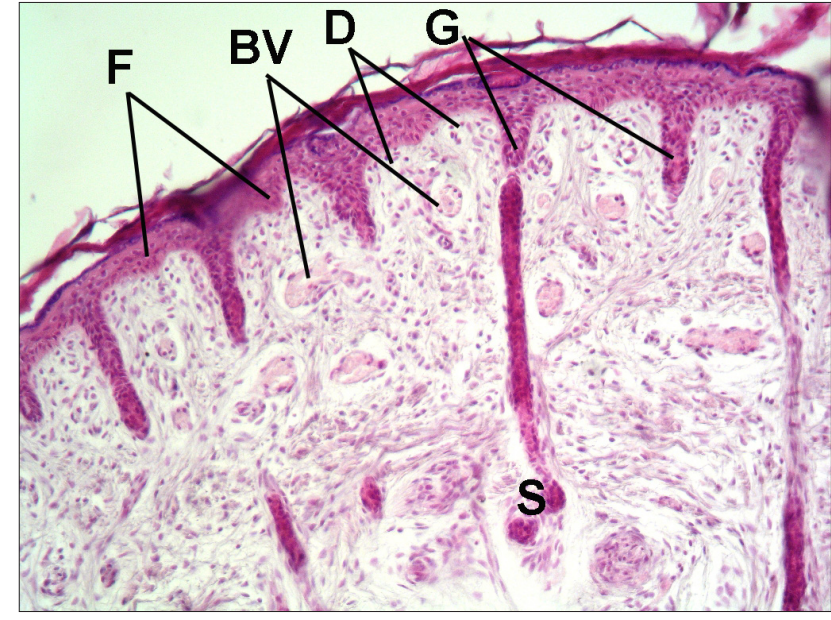

Fig. 13. Transversal section shows the epidermal glandular folds $(\mathrm{G})$, secondary dermal ridges (D), furrow folds (F) and sweat glands (S) of 22-week-old fetus. All layers of epidermis are already developed. Dermis is richly vascularized by blood vessels (BV). (hematoxylin and eosin, Magn. 200x).

Advantages of our methodological approach are as follows:

- More effective observation,

- Observation of more objects simultaneously,

- Observation of the future dermatoglyphic pattern on volar surface sections,

- Better comparison of different structures,

- Simultaneous observation of different planes on a single glass slide,

- Simultaneous observation enables a more precise assessment of a chronological/temporal difference during development.

\section{DISCUSSION}

The observation of papillary ridge morphogenesis occurring in the volar skin from a horizontal perspective presents a daunting methodological challenge. Embedding the tissue in paraffin and histological preparation provide an improved overview of the tissue. The major problem is the appropriate orientation of the hands/feet and fingers/ toes in the process of embedding to achieve the required observation view of the section under a light microscope. We have used special techniques for the embedding and tissue cutting processes.

The crucial events for the establishment of the epidermal ridge pattern occur from the $10^{\text {th }}$ to $16^{\text {th }}$ week of prenatal development.

Our observations of finger pad development and the development of epidermal glandular folds as well as our previous studies ${ }^{2,30-32}$ agreed with other authors, e.g. Cummins $^{20}$, Hale $^{33}$, Penrose and O'Hara ${ }^{34}$ or Okajima ${ }^{27}$. We can confirm that there is a rich supply of dermis with blood vessels during volar pad and epidermal glandular fold formation. Therefore we are in agreement with the

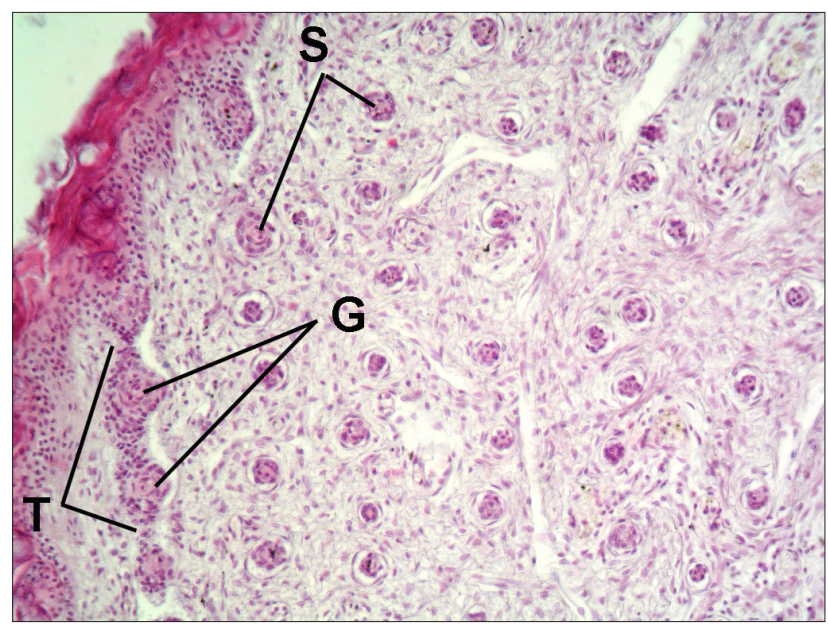

Fig. 14. Tangential section shows the last stage of papillary ridges development (26-week-old embryo). The transversal dermal furrows (T) appear on the secondary dermal ridges $(\mathrm{G})$ and first dermal papillae are formed. In the dermis the sweat glands ducts are visible $(\mathrm{S})$. (hematoxylin and eosin, Magn. 200x).

claims made by Blechschmidt ${ }^{35}$ and Okajima ${ }^{29}$ concerning the important role of skin vascularization. Our results also confirm the views of Babler ${ }^{3}$, Bonnevie ${ }^{11}$, Hale ${ }^{33}$, and Okajima $^{27}$, that is the initial phase of epidermal glandular fold development the most important phase of papillary ridge formation. Our observations concerning the directions of the volar pad formation and of the epidermal glandular/furrow folds are almost identical to other studies. However, differing from some other studies ${ }^{36}$, we also observed proximal finger pads but no central palm pads.

The factors that may have an influence on the ridge configuration are not definitely identified. Various hypotheses are known about the factors influencing papillary ridge development. They were recently reviewed by Kücken ${ }^{16}$ :

- The folding hypothesis (originally called growth stress theory). Kollman ${ }^{37}$ was the first to examine the question of what determines the alignment of epidermal ridges. He suggested that the ridge direction was greatly influenced by growth stress and compressions in the developing skin. This folding hypothesis was tested by computer experiments and mathematical analysis by Kücken and Newell ${ }^{15}$,

- The nerve hypothesis. Several studies suggest that the nervous system plays an important role in the development of the papillary ridge formation. According to Moore and Munger ${ }^{26}$ the dermatoglyph can reflect the ontogeny of the afferent nervous system that occurred prior to papillary ridge development. Afferent nerve fibers provide a two-dimensional grid that could modulate the spacing and arrangement of the papillary and sweat duct ridges of successive digits ${ }^{24}$. Bonnevie ${ }^{17}$ also suggested that there is a direct relationship between cutaneous nerve distribution and the location of the centers of ridge patterns. We also found parallel fine nerve fibers in the superficial dermis, which probably 
innervated the overlying epidermis, of all digital and palmar pads in 12-week-old embryo (Fig. 5a),

- The fibroblast hypothesis. Green and Thomas ${ }^{38} \mathrm{ob}-$ served that in vitro cultivated keratinocytes form directional patterns that are reminiscent of whorls or triradii.

Our observations confirm to the hypothesis that the increased vascularization of dermis considerably affects papillary ridges formation (see Fig. 11).

Identification of developing papillary traits is already possible during fetal life (about $15^{\text {th }}-16^{\text {th }}$ week of prenatal development). Tangential plane of volar skin paraffin sectioning enables observation and examination of the future dermatoglyphic pattern with light microscopy. Appropriate embedding, as well as paraffin section orientations are essential methodological prerequisites. Our new methodological approach has considerably rationalized our work enabling us to observe the entire volar surface, as well as making simultaneous observations of the volar surface on hands and feet. The Okajima's method ${ }^{29}$ offered a three-dimensional view of papillary ridge development and dermatoglyphic pattern formation. Comparing the results from both the histological and Okajima's methods ${ }^{29}$, we have come to the same conclusions regarding the chronology of papillary ridge development. A developmental study of the serial histological section might be advantageous, since it would offer a more detailed evaluation of the changes of histological structures at the sites of papillary ridge formation.

\section{CONCLUSION}

Volar pad development and papillary ridge formation are identical on the hands and feet, but the developmental stages on feet lag one week behind those of hands. Papillary ridge embryogenesis follows the craniocaudal developmental direction. At the beginning of the $3^{\text {rd }}$ month an early stage of papillary ridge development starts. After developmental week 14 the configuration of the future dermatoglyphic pattern already occurres at the epidermal-dermal junction. We consider the $6^{\text {th }}$ month of prenatal development to be the gestational age when the papillary ridge development is completed.

\section{REFERENCES}

1. Hamrick MW. Evolution and development of mammalian limb integumentary structures. J Exp Zool (Mol Dev Evol) 2003; 298B:152-63.

2. Pospíšil MF, Pospíšilová V, Kajabová H. Formation of the papillary surface of the hands and feet in prenatal development in man. Bratisl Lek Listy 1989; 90 (7): 499-506.

3. Babler WJ. Embryologic development of epidermal ridges and their configurations. Birth Defects Orig Artic Ser 1991; 27(2):95-112.

4. Morohunfola KA, Jones TE, Munger BL. The differentiation of the skin and its appendages. I. Normal development of papillary ridges. Anat Rec 1992; 232(4):587-98.
5. Morohunfola KA, Jones TE, Munger BL. The differentiation of the skin and its appendages. II. Altered development of papillary ridges following neuralectomy. Anat Rec 1992; 232(4):599-611.

6. Kimura S. Embryologic development of flexion creases. Birth Defects Orig Artic Ser 1991; 27(2):113-29.

7. Kahn HS, Graff M, Stein AD, Zybert PA, McKeague IW, Lumey LH. A fingerprint characteristic associated with the early prenatal environment. Am J Hum Biol 2008; 20(1):59-65.

8. Godfrey KM, Barker DJ, Peace J, Cloke J, Osmond C. Relation of fingerprints and shape of the palm to fetal growth and adult blood pressure. BMJ 1993; 307(6901):405-9.

9. Shield JPH, Wadsworth EJK, Hobbs K, Baum JD. Dermatoglyphics, fetal growth, and insulin dependent diabetes in children under 5 years. Arch Dis Child 1995; 72:159-60.

10. Kahn HS, Graff M, Stein AD, Lumey LH. A fingerprint marker from early gestation associated with diabetes in middle age: the Dutch Hunger Winter Families Study. Int J Epidemiol 2009; 38(1):101-9.

11. Bonnevie K. Studies on papillary patterns of human fingers. J Genet 1924; 15:1-111.

12. Siváková D, Scheil HG, Schmidt HD, Vulpe C. Population affinities assessed by dermatoglyphic and hemogenetic variables. Anthropol Anz 2007; 65(2):137-46.

13. Scheil HG, Schmidt HD, Baltova S, Djordjevic D, Vulpe C, Siváková D, Efremovska L. Dermatoglyphic studies in eastern and south-eastern Europe. Anthropol Anz 2005; 63(4):393-9.

14. Siváková D, Pospísil M. Dermatoglyphic analysis of Habans (Hutterites) from Slovakia. Anthropol Anz 2001; 59(4):355-63.

15. Kücken M, Newell AC. Fingerprint formation. J Theor Biol 2005; 235(1):71-83.

16. Kücken M. Models for fingerprint pattern formation. Forensic Sci Int 2007; 171(2-3):85-96.

17. Bonnevie K. Die ersten Entwicklungsstadien der Papillarmuster der menschlichen Fingerballen. Nyt Mag f Naturv 1927; 65:19-56.

18. Bonnevie K. Zur Mechanik der Papillarmusterbildung. Die Epidermis als formativer Faktor in der Entwicklung der Fingerbeeren und der Papillarmuster. Arch f Entw 1929; 117:384420.

19. Cummins H. Epidermal-ridge configurations in developmental defects, with particular reference to the ontogenetic factors which condition ridge direction. Am J Anat 1926; 38:89-151.

20. Cummins H. The topographic history of the volar pads (walking pads, Tastballen) in the human embryo. Contrib Embryol Carnegie Inst Wash 1929; 20:103-26.

21. Tedde Piras A, Pirino A, Tedde G. Development of human fetal skin from the beginning of pregnancy to the 6th month. Light microscopy study. Bull Assoc Anat (Nancy) 1984; 68(200):71-6.

22. Misumi Y, Akiyoshi T. Scanning electron microscopic structure of the finger print as related to the dermal surface. Anat Rec 1984; 208(1):49-55.

23. Lacroix B, Wolff-Quenot MJ, Haffen K. Early human hand morphology: an estimation of fetal age. Early Hum Dev 1984; 9(2):12736.

24. Dell DA, Munger BL. The early embryogenesis of papillary (sweat duct) ridges in primate glabrous skin: the dermatotopic map of cutaneous mechanoreceptors and dermatoglyphics. J Comp Neurol 1986; 244(4):511-32.

25. Moll I, Moll R, Franke WW. Formation of epidermal and dermal Merkel cells during human fetal skin development. J Invest Dermatol 1986; 87(6): 779-87.

26. Moore SJ, Munger BL. The early ontogeny of the afferent nerves and papillary ridges in human digital glabrous skin. Brain Res Dev Brain Res 1989; 48(1):119-41.

27. Okajima M. Development of dermal ridges in the fetus. J Med Genet 1975; 12:243-50.

28. Streeter GL. Weight, sitting height, head size, foot length and mestrual age of the human embryo. Contrib to Embryol 1920; 55:145-70.

29. Okajima M. A methodological approach to the development of epidermal ridges viewed on the dermal surface of fetuses. Prog Clin Biol Res 1982; 84:175-88. 
30. Pospíšilová-Zuzáková V. Prvé vývojové štádiá papilárnych základov na prstoch nôh (Article in Slovak, The first developmental stages of papillary primordias on toes). Acta Facultatis Rerum Naturalium Univ Comen Antropologia 1962; VIII (3-5):175-82.

31. Pospisilova-Zuzakova V. Determination of the body length of the fetus with the aid of the length of the sole of the foot. Biologia 1962; 17:49-52.

32. Pospíšilová V, Kajabová H. Formovanie epidermo-dermálneho spojenia pokožky hrubého typu u l'udských fétov (Article in Slovak, Development of epidermo-dermal junction of thick type of skin in human fetuses). Plzeň Lék Sborn 1991; 63:269-71.

33. Hale AR. Morphogenesis of volar skin in the human fetus. Am J Anat 1952; 91:147-73.
34. Penrose LS, O'Hara T. The development of epidermal ridges. J Med Genet 1973; 10:201-8.

35. Blechschmidt E. Die embryonalen Gestaltungfunktionen der menschlichen Oberhaut. II. Mitt. Die Entstehung des Papillarkörpers in den proximalen und distalen Abschnitten der Fingerbeere. Z Morphol u Anthrop 1963; 54 (2):163-72.

36. Mulvihill JJ, Smith DW. The genesis of dermatoglyphics. J Pediatr 1969; 75:579-89.

37. Kollmann A. Der Tastapparat der menschlichen Rassen und der Affen in seiner Entwickelung und Gliederung. Leipzig: Leopold Voss Verlag, 1883.

38. Green H, Thomas J. Pattern formation by cultured human epidermal cells: development of curved ridges resembling dermatoglyphs. Nature 1978; 200:1385-8. 